\title{
Iniciativas para conservar la biodiversidad
}

\author{
Anamaría Varea*
}

\section{Introducción}

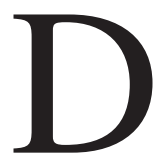

esde mediados de los años 90, gobiernos, organizaciones ambientalistas, sectores productivos y movimientos sociales, incorporan, en sus agendas, propuestas de manejo y conservación de la biodiversidad ${ }^{1}$. Esta se refiere a la diversidad de la vida, concepto que adquiere relevancia a partir de la vigencia del Convenio sobre Diversidad Biológica, definido en la Cumbre de las Naciones Unidas sobre Medio Ambiente y Desarrollo (CNUMAD o Rio 92), en la que se reconoce la soberanía de los estados sobre la biodiversidad, se abre el debate respecto a este tema y se determina que el país empiece a definir estrategias de manejo, de control y regulación de este recurso clave.

La biodiversidad es un recurso indispensable pues muchos de nuestros intereses y necesidades cotidianas se relacionan con el manejo y conservación de la biodiversidad: la alimentación, la vivienda, el transporte, la salud, entre otros aspectos; se relaciona directamente con los recursos naturales disponibles para satisfacer las elementales de las poblaciones locales. La conservación y manejo del entorno natural son claves para el bienestar y desarrollo humano.

\footnotetext{
* Coordinadora Nacional del Programa de Pequeñas Donaciones de las Naciones Unidas-Ecuador.

1 Biodiversidad es la variabilidad de organismos vivos de cualquier fuente, incluidos, entre otras cosas, los ecosistemas terrestres y marinos y otros ecosistemas acuáticos y los complejos ecológicos de los que forman parte; comprende la diversidad dentro de cada especie, entre las especies y de los ecosistemas, como resultado de procesos naturales y culturales.
} 
Los recursos naturales son la base de la subsistencia del ser humano, de ellos hemos dependido y dependemos para la satisfacción de las necesidades básicas, a través del uso, acceso y control de la biodiversidad. Los ejemplos que ilustran esto son numerosos y se refieren a especies que han sido domesticadas y cuyo uso actualmente es cosmopolita: el arroz, la quinina, el cacao, el banano, el camarón de piscina, la guadua, especies forestales maderables, etc.

La domesticación de especies silvestres, en la mayoría de los casos, tiene que ver con prácticas tradicionales comunitarias. Un proceso de selección de variedades, que han sido domesticadas y en muchos casos comercializadas, demuestra el conocimiento del entorno que tenían las comunidades campesinas e indígenas.

El manejo y conservación de la biodiversidad es un patrimonio valioso y una urgencia para el planeta, ya que de esta depende la estabilidad climática, la protección de las cuencas hidrográficas, la seguridad alimentaria y el equilibrio de los procesos ecológicos.

Este documento se divide en tres partes. En la primera parte: Ecuador megadiverso, se hace un recuento de las estrategias para manejarlo y conservarlo. Se habla del sistema nacional de las áreas protegidas como estrategia para salvaguardar la biodiversidad. En el análisis se mencionan algunas dificultades para la conservación y manejo de la biodiversidad en Ecuador.

La segunda parte: Está dividida en dos capítulos, que nos hablan tanto de iniciativas para abordar la biodiversidad, cuanto de los problemas que afectan su conservación. El primero analiza la problemática ambiental en el área rural, y la segunda lo hace en las zonas pobladas. Este análisis se justifica pues permite conocer el escenario en el que se apoyan las iniciativas locales el PPD. El primer capítulo Deterioro ambiental y biodiversidad, hace un recorrido por las cuatro regiones del país y analiza la situación ambiental. El itinerario se inicia por Galápagos, región megadiversa por excelencia y primera área natural protegida, que constituye una marca de identidad ecuatoriana ${ }^{2}$. La segunda región que concita la atención mundial por su biodiversidad es la Amazonia, región en la que también se hace un rápido reconocimiento para delinear la situación de la biodiversidad. El recorrido continúa por la

\footnotetext{
2 Galápagos marca de identidad, es el nombre de la campaña de difusión que se lanzó en el 2003 y que ha generado diversas reacciones en la ciudadanía.
} 
Sierra ecuatoriana y termina en la Costa. A través del análisis se identifican las potencialidades de cada región con respecto a la biodiversidad, se da cuenta de las actividades productivas relevantes en la zona y los impactos socioambientales.

El segundo capítulo, Deterioro ambiental en centros poblados, enfoca el tema de la contaminación y deterioro ambiental en áreas urbanas y revisa la insuficiente planificación de los centros poblados, donde la ausencia de estrategias que mitiguen los impactos ambientales, causa contaminación de aire, agua y suelo y afecta a la biodiversidad.

El manejo y conservación de la biodiversidad, actualmente, se trabaja desde el concepto de desarrollo sostenible, con una visión integral que considera factores sociales y económicos interrelacionados con ciclos naturales y ecológicos en el proceso de desarrollo ${ }^{3}$. Bajo estas consideraciones en la tercera parte: Propuestas participativas y diversas se analiza el caso del Programa de pequeñas donaciones, como una experiencia que apoya iniciativas locales en el manejo y conservación de la biodiversidad en 64 países y trabaja en Ecuador desde hace 10 años.

\section{Ecuador megadiverso}

La conservación de la biodiversidad en Ecuador es relevante pues el país es megadiverso. La línea ecuatorial, la presencia de los Andes y el hecho de que sus costas den hacia el océano Pacífico y reciban la influencia de dos corrientes con características muy diferentes, ha dado paso a una variedad de elementos naturales, donde las comunidades bióticas se han adaptado a las cambiantes circunstancias del medio, presentando una marcada riqueza biológica. Ecuador tiene bosques húmedos tropicales, bosques nublados, páramos, arrecifes coralinos,

3 La propuesta que emergió como resultado de la Cumbre de las Naciones Unidas para el Medio Ambiente y Desarrollo, que tuvo lugar en 1992 en Rio de Janeiro y fue ratificada y fortalecida en la Cumbre de Johannesburgo en agosto del 2002. Desarrollo sostenible es aquel que satisface las necesidades del presente sin comprometer la capacidad de las futuras generaciones para satisfacer sus propias necesidades.

- UICN. PNUMA. WWF. 1991. "Cuidar la Tierra”. Gland-Suiza.

- BID-PNUD. "Nuestra propia Agenda". Comisión de Desarrollo y Medio Ambiente de América Latina y el Caribe.

- CEPAL. "Desarrollo sustentable equidad y medio ambiente". Santiago. 1991. 
manglares, bosques secos costeros, playas, estuarios, sabanas, islas y muchos hábitats más. El país cuenta con variedad de recursos naturales, pisos ecológicos, climas, y posee un mar territorial de $1060053 \mathrm{~km}^{2}$ y 2 625 kilómetros de costa marina continental.

En este entorno diverso se han desarrollado un sin número de culturas, pueblos, nacionalidades, que han dado paso a que el Ecuador cuente con una riqueza cultural y étnica. Muchas de estas nacionalidades tienen prácticas tradicionales y culturales para el manejo de la biodiversidad, que se ponen de manifiesto en el manejo del territorio, en prácticas productivas amigables con el entorno, la selección de cultivos, elaboración de artesanías, construcción de viviendas, prácticas de curación, entre otras.

La megadiversidad que tiene el Ecuador, el esquema de desarrollo de sus actividades productivas -basado en la extracción de recursos naturales y en la agricultura-, y sus numerosas comunidades locales y pueblos indígenas que manejan el entorno natural, determinan la importancia que tiene para el país en conservar su biodiversidad.

La importancia de la conservación de la diversidad biológica en su valor: ecológico, ético, social y cultural y el valor económico ${ }^{4}$.

El valor ecológico de la biodiversidad tiene que ver con las funciones reguladoras de los procesos ecológicos y las interacciones entre los diversos organismos y su entorno. La estabilidad climática, protección de cuencas hidrográficas y de áreas sensibles a la erosión y el control de la sedimentación, se relacionan con la funciones reguladoras. La naturaleza, en buen estado, fija la energía solar y permite la producción de biomasa, el almacenamiento y reciclaje de materia orgánica y nutrientes, el control biológico de plagas y el mantenimiento de los procesos evolutivos. La renovación de los recursos vitales (agua, aire y suelo) depende de la protección de la biodiversidad.

Todo ser vivo tiene derecho a existir, más allá de la utilidad que tenga para la humanidad, es el principio que sustenta el valor ético de la diversidad biológica. Ese se fundamenta en el respeto del ser humano hacia la naturaleza y en los esfuerzos que se hacen para mantener la armonía y el balance con ella.

Es necesario considerar, además, la importancia científica de la biodiversidad. El conocimiento de los procesos naturales permite un ade-

\footnotetext{
4 Suárez, L., 1997, "La Biodiversidad en Ecuador" en: Varea Anamaría (comp.). 1997. "Biodiversidad. Bioseguridad y Biopiratería". ILDIS. Abya-Yala. Instituto de Estudios Ecologistas del Tercer Mundo y Revista Biodiversidad. Quito-Ecuador.
} 
cuado manejo de los recursos y afirma los valores de respeto e integración a la naturaleza. En esta línea, el debate ha adquirido trascendencia frente a las perspectivas que abre la biotecnología en el campo de manipulación genética.

El valor social y cultural de la biodiversidad se relaciona con el uso que los distintos grupos dan a la diversidad de la vida y se evidencia en la variedad de lenguas, costumbres y creencias, así como en los mitos, ritos y símbolos; en las expresiones artísticas; en las estructuras sociales y en cómo maneja su entorno natural las comunidades locales y poblaciones indígenas. Diversos procesos sociales y culturales están relacionados directamente conque los ecosistemas sigan funcionando adecuadamente. Es necesario tener presente que las necesidades humanas no son solo productivas y reproductivas sino que tienen que ver con necesidades recreativas, estéticas, espirituales, de protección y seguridad, de libertad, soberanía y socialización.

El desarrollo y el manejo de la biodiversidad determinan el valor económico de este recurso. En Ecuador muchas actividades productivas dependen de los recursos que ofrece la naturaleza: agricultura, pesca, industria maderera, acuicultura, artesanía, medicina natural, ecoturismo, entre otras. La economía del país está sustentada, en su mayor parte, en la extracción de recursos naturales y la seguridad alimentaria se sustenta, principalmente, en que se mantengan formas de cultivo y de material genético que se conserva en las variedades silvestres que no han sido domesticadas o desarrolladas. La conservación y el manejo de este recurso es fundamental pues las especies y variedades silvestres son la fuente de nuevas medicinas, aceites, bioquímicos, fibras, materias primas para la construcción, energía, entre otras.

\section{Estrategias para la conservación de la biodiversidad}

Si bien en Ecuador ha habido avances en lo que respecta a las políticas ambientales, no es menos cierto que los impactos sobre el entorno natural y social siguen en aumento. Una breve revisión del marco legal para la conservación de la biodiversidad, resulta útil para entender el escenario de país respecto a este desafío.

La conservación y el manejo de la diversidad biológica son básicos para un desarrollo ambientalmente sano y socialmente justo. Las 
estructuras, funciones y diversidad de los sistemas naturales deben manejarse y protegerse, para ello se incluye la protección de las especies silvestres en reservas naturales o áreas protegidas y el mantenimiento de los procesos ecológicos y la riqueza genética en todo el territorio nacional, inclusive en áreas agrícolas y en otros ecosistemas que han sido transformados por el ser humano.

El Convenio de Diversidad Biológica señala un conjunto de obligaciones frente a la conservación de la biodiversidad y determina que la conservación in situ es primordial para lograr este objetivo. Esto se refiere a la preservación de áreas con una considerable biodiversidad local, lo que se conoce como parques nacionales o reservas naturales. El Ecuador cuenta con una Sistema Nacional de Áreas Naturales Protegidas (SNAP).

Existe también la conservación ex situ, es decir, el mantenimiento de los componentes de diversidad biológica fuera de sus hábitats naturales, esto se conoce como bancos de germoplasma, colecciones de campo o manejo de especies en cautiverio. Los programas de conservación ex situ deben ser parte de los programas de protección de especies y recursos genéticos como un complemento para la conservación in situ ${ }^{5}$.

\section{Áreas naturales protegidas}

Las áreas naturales protegidas constituyen una de las principales medidas que permiten la conservación in situ de la biodiversidad silvestre. El objetivo principal es preservar zonas con características ecológicas especiales, que se conviertan en bancos naturales, sustentadores de vida para las presentes y futuras generaciones. En estas áreas se conservan ecosistemas frágiles y se preservan poblaciones de especies en peligro de extinción. Aquí también se conservan recursos genéticos, al mantener parientes silvestres de las especies cultivadas. Los criterios para el establecimiento de estas áreas son: diversidad, fragilidad intrínseca, vulnerabilidad, endemismo, uso actual y potencial, entre otros.

\footnotetext{
5 Josse, Carmen, 2001, "La biodiversidad en el Ecuador - el Informe 2000", MAE, Ecociencia, Quito.
} 
El Sistema Nacional de Áreas Naturales Protegidas (SNAP) de Ecuador es responsabilidad del Ministerio del Ambiente que maneja y controla estas áreas, en las que, por ley, se prohíbe o restringe el uso de los recursos naturales. A partir de una estrategia nacional, elaborada en 1976, replanteada en 1989 y en 1999 (Plan Estratégico del Sistema Nacional de Áreas Protegidas del Ecuador), se declara áreas de reserva natural a aquellas que presentan un alto grado de biodiversidad, en las que la intervención del ser humano ha sido mínima y por lo tanto su territorio está relativamente inalterado. Estas se decretan según la Ley forestal cuya jurisdicción la tiene el Ministerio del Ambiente ${ }^{6-7}$.

Desde 1990 en el país se han desarrollado diversas acciones para fortalecer el SNAP, sin embargo, la falta de respaldo financiero impide llevar a cabo todas las actividades que le corresponden por mandato. El SNAP comprende el 18\% del territorio terrestre nacional (4 719871 hectáreas) y tiene a su cargo un área marina de 14124430 hectáreas. Para el año 2000 el SNAP lo conforman 26 áreas naturales: 23 son continentales, 2 insulares y 1 es reserva marina. En 1999 se declararon dos zonas intangibles: Cuyabeno e Imuya, que incluyen el reconocimiento de territorios indígenas en la Amazonia y establecen un mecanismo de protección de estas tierras para asegurar la conservación de este espacio de vida de los pueblos Tagaeri y Taromenane.

Como parte de las estrategias de conservación está también el Patrimonio Forestal del Estado en el que están las categorías de bosque protector y reserva forestal. Es importante señalar que dos áreas naturales protegidas fueron declaradas, por la UNESCO, como Patrimonio de la Humanidad: Galápagos y Sangay.

En Ecuador, si bien el principio de preservación ecológica tiene vigencia, la práctica muestra que esta es confusa, puesto que se realizan actividades productivas a gran escala en estas áreas y se han otorgado concesiones petroleras y mineras dentro de las áreas de reserva. En 7 de las 8 áreas protegidas de la Amazonia existe presión por parte de actividades petroleras; el caso más dramático es la Reserva Biológica Limoncocha, donde el 99,81\% de su extensión está afectada por la actividad petrolera. Por otra parte, en 11 de las 25 áreas naturales protegidas se realizan actividades mineras.

\footnotetext{
6 Josse, Carmen, 2001, Op. Cit. pp. 152.

7 Informe Nacional de Biodiversidad - pág. 158, 182.
} 
Las actividades industriales que más afectan a las áreas naturales protegidas son la pesca, la industria camaronera y la industria maderera. En la Costa seis áreas protegidas enfrentan fuertes presiones por las actividades señaladas.

Desde mediados del año 90 y tantos, la gestión y manejo de las áreas protegidas ha incorporado estrategias participativas, a fin de que las poblaciones locales se integren en el manejo y conservación del área. Este nuevo enfoque es fundamental, pues la mitad de las áreas protegidas están habitadas por grupos campesinos, nacionalidades indígenas y grupos étnicos ${ }^{8}$.

Otra estrategia para la conservación de la biodiversidad son las reservas privadas. Según un estudio realizado por la Fundación Natura publicado en 1999, hasta 1998 habían 154 reservas privadas que cubrían una extensión 2390000 hectáreas, aproximadamente: 61,8\% de reservas está en la Sierra, en la Costa hay el $25 \%$ y en la Amazonia $13,2 \%$. Estas zonas son administradas por entidades privadas: ONG, universidades, operadores turísticos y personas particulares, además, de algunos organismos seccionales que tienen a su cargo estas reservas.

\section{Conservación de la agrobiodiversidad}

Prácticas tradicionales de comunidades indígenas y campesinas, con un gran conocimiento de su entorno natural, permitieron la domesticación de plantas y la selección de variedades agrícolas. Los ejemplos relativos al manejo de la agrobiodiversidad son múltiples: arroz, quinina, cacao, papas, banano, son algunas plantas cuyos parientes silvestres estaban en países en vías de desarrollo y que han sido domesticadas. Actualmente, el uso de estos productos es cosmopolita y las ganancias que estos han generado son probablemente incalculables. Entre los casos de plantas originarias de América Latina, cuyo uso es mundial para la alimentación, se destacan el maíz, la papa y el tomate. Entre las especies originarias de Ecuador que se utilizan para la medicina se destaca la Cinchona $s p$, que sirve para sintetizar la quinina, principio activo para combatir la malaria.

\footnotetext{
8 Varea Anamaría (comp.). 1997. "Biodiversidad. Bioseguridad y Biopiratería". ILDIS. Abya-Yala. Instituto de Estudios Ecologistas del Tercer Mundo y Revista Biodiversidad. Quito-Ecuador.
} 
En el país la agricultura, a pequeña y a gran escala, es una actividad fundamental para el desarrollo del país. La agrobiodiversidad del país ha sido creada, fundamentalmente, por comunidades indígenas y campesinas. Este recurso se está perdiendo debido a la modernización de las prácticas agrícolas y la imposición de paquetes tecnológicos que imponen ciertas variedades, tienden al monocultivo y determinan la erosión genética, es decir, la desaparición de los recursos genéticos almacenados en las especies y variedades cultivadas.

La conservación de agrobiodiversidad in situ se refiere a la protección de especies silvestres emparentadas a las plantas cultivadas en áreas naturales y el mantenimiento en áreas agrícolas de variedades locales o primitivas que han sido cultivadas por los campesinos e indígenas durante siglos. La conservación de la biodiversidad agrícola ex situ tiene que ver con el almacenamiento de recursos genéticos en bancos de germoplasma, y con el establecimiento de colecciones de campo y manejo de especies en cautiverio.

El manejo y conservación de la biodiversidad agrícola es prioritario en países como el Ecuador, en el que existe una megadiversidad y un conocimiento ancestral del uso de los recursos del entorno. La agrobiodiversidad adquiere relevancia pues la satisfacción de las necesidades alimenticias y medicinales de la mayoría de la población mundial se sustenta en el uso de los recursos biodiversos y en el conocimiento comunitario tradicional. Manejar y conservar la biodiversidad agrícola y silvestre del país es prioritario para mejorar la producción de alimentos y fibras naturales, proveer materia prima para la investigación científica y médica y ofrecer opciones para el aprovechamiento sostenible de los recursos biológicos.

En Ecuador el germoplasma nativo, proveniente de especies silvestres y de variedades locales, es colectado libremente por investigadores de otros países para desarrollar variedades mejoradas, que retornan al país como paquetes tecnológicos sofisticados y costosos. En este escenario no solo existe una pérdida de variabilidad de muchos cultivos sino también una fuga de recursos fitogenéticos, desde países ricos en germoplasma, como el Ecuador, hacia países ricos en industria y tecnología agrícola; esto ha sido denunciado en varios estudios, publicaciones y presenta- 
ciones en foros nacionales e internacionales por varias organizaciones e investigadores, entre las que se destacan las de Elizabeth Bravo9.

En Ecuador, en las tres regiones continentales, diversas comunidades trabajan en la recuperación de la agrobiodiversidad. En la región andina hay iniciativas que buscan rescatar variedades de cereales y tubérculos nativos andinos; en la Amazonia se está trabajando en el rescate de frutas, variedades de yuca y naranjilla y en la Costa en la conservación y manejo de variedades de maíz ${ }^{10}$.

\section{Desarrollo, ambiente y biodiversidad}

En Ecuador las actividades productivas dependen directamente de los recursos naturales y de la biodiversidad. Este es el país, de América Latina, con el mayor peso de productos primarios en sus exportaciones $(90 \%)^{11}$. La presión sobre el ambiente y la biodiversidad es cada vez más marcada, lo que pone en riesgo las actividades productivas a mediano y largo plazo. Por otro lado, las economías locales también se sustentan en actividades productivas cuya base es el patrimonio natural, cuya explotación y escasez está determinando la aparición de conflictos socioambientales en todo el país ${ }^{12}$.

La multiplicidad de verdes paisajes, en la Sierra, Costa y Amazonia y la exuberancia de bosques y manglares, se transforman aceleradamente debido a un agresivo proceso de deforestación resultado de la

9 Coordinadora Ecuatoriana de Agroecología. 1997. "Agroecología: Tres opciones sustentables". CEA. Terranuova. Heifer Project. Quito-Ecuador.

- RIAD. 1993. "Agricultura Sustentable en América Latina: aspectos centrales de un debate en curso". No. 1. Serie Cuadernos Temáticos. Santiago-Chile. 10 CEPAL, Anuario Estadístico 1999

11 Varea Anamaría et al. 1997. "Ecologismo Ecuatorial: conflictos socioambientales y movimiento ecologista en el Ecuador" Abya-Yala. CEDEP. Quito-Ecuador. 12 Informe Nacional de Biodiversidad del año 2000. 
explotación forestal, la expansión de la frontera agrícola, la conversión de bosques en plantaciones agroindustriales, las actividades de acuicultura en la faja costera, los procesos de colonización, el crecimiento urbano y al impacto provocado por la explotación petrolera y minera.

Muchos sectores entienden el desarrollo solamente como el crecimiento económico, a través del cual se plantea el progreso de la sociedad. Si bien toda actividad humana tiene un impacto sobre el ambiente, es necesario considerar que el aumento de las actividades económicas y productivas y la explotación acelerada de los recursos naturales ponen en evidencia que el ambiente y la naturaleza tienen límites. En el país los síntomas del deterioro ambiental y las amenazas sobre la biodiversidad, se hacen cada vez más evidentes, hay aumento de los niveles de contaminación, destrucción ecológica y degradación ambiental, que colocan en serio riesgo este recurso estratégico y el desarrollo del país.

En Ecuador la principal amenaza para la pérdida de hábitats y su biodiversidad es la deforestación. Esta aumenta debido a la expansión de la frontera agrícola, a los procesos de colonización, el crecimiento urbano y al aumento de actividades productivas a gran escala como la explotación petrolera y minera, la producción camaronera, bananera, palmicultora y florícola.

El país cuenta con diversos datos sobre deforestación pero no existe un dato certero y menos aún tasas anuales que permitan comparar el incremento en la desaparición de los bosques. De 1980 a 1990 las tasas de deforestación a nivel nacional varían entre 0,5 y $2,4 \%$ y presentan distintos niveles de gravedad en las cuatro regiones del país. La FAO ubica al Ecuador con la tasa de deforestación de 189000 hectáreas por año. Según estudios realizados por Rodrigo Sierra, publicados en 1999, para 1996 el Ecuador contaba con menos del 60\% de los bosques del país ${ }^{13}$.

Derivados de la deforestación y la consecuente ampliación de la frontera agrícola se presentan varios problemas ecológicos adicionales como la pérdida de especies, la erosión y la sedimentación.

La extinción de las especies altera el equilibrio de los ecosistemas y se pierden para siempre valores culturales fundamentales para las

13 Carrasco Alfredo. 1992. "Islas Galápagos: una visión actual", en ¿espacios sin habitantes? parques nacionales en América del Sur. Stephen y Thora Amend (editores). UICN-Editorial Nueva Sociedad. Caracas-Venezuela. 
comunidades campesinas e indígenas del país, lo que tarde o temprano se traduce en pérdidas económicas significativas.

Ambiental y biodiversidad

\section{Islas Galápagos}

La historia natural de Galápagos determina que este archipiélago sea considerado como un sitio sobresaliente en biodiversidad a nivel mundial, por las diversas adaptaciones de flora y fauna a formaciones volcánicas agrestes y áridas. Las islas se formaron por procesos volcánicos que tuvieron lugar hace 3 y 5 millones de años. El archipiélago se encuentra a $1200 \mathrm{~km}$ de la costa ecuatoriana y está conformado por 13 islas grandes, seis pequeñas y más de cuarenta islotes y rocas.

$\mathrm{El}$ alto grado de endemismo y la alta biodiversidad responde al hecho de que los organismos que arribaron a las islas tuvieron que atravesar, por sus propios medios, las 600 millas que separan al archipiélago del continente y una vez allí debieron establecerse en un medio hostil, lo que implicó un proceso de adaptación y evolución.

Desde que el ser humano arribó a las Galápagos, se inició la transformación del ambiente y el impacto sobre el entorno natural. Las islas fueron descubiertas en 1535. A fin de conservar las islas y disminuir los impactos ambientales se establecieron medidas a nivel nacional e internacional. En 1934 Ecuador declaró a Galápagos como área de conservación, sin embargo, fue en 1959 en que se declaró al archipiélago como Parque Nacional. En este mismo año, como parte de la celebración del centenario de la publicación de El origen de las especies, de Charles Darwin, se creó la Fundación Científica Charles Darwin, y un año más tarde la Estación Darwin en Puerto Ayora. Las islas son además Patrimonio Natural de la Humanidad ${ }^{14}$. Galápagos ha sido denominada

\footnotetext{
14 Carrasco Alfredo. 1992. "La investigación en las Galápagos: un aporte a la conservación", en La Investigación para la Conservación de la Diversidad Biológica en el Ecuador - Memorias del Simposio llevado a cabo del 10-12 de junio de 1992. Patricio Mena y Luis Suárez. Editores. Ecociencia. Quito-Ecuador.
} 
como la Vitrina de la Evolución por la oportunidad que presenta para hacer investigación científica ${ }^{15}$.

La conservación de las islas se ve afectada por la creciente presencia de especies introducidas por el ser humano que han causando serios impactos en la flora y la fauna, e incluso han determinado la extinción de varias especies. Además, el aumento del turismo ${ }^{16}$ hacia Galápagos ha dado paso a un crecimiento explosivo de la población, pues el incremento de infraestructura local determinó un aumento de la migración, ya que se requerían servicios en mar y en tierra ${ }^{17}$.

En 1974, 4078 personas poblaron cuatro de las islas del Archipiélago, las que en 1990 ya eran 9785 y según el censo de 2002 son aproximadamente 16 000. Las islas habitadas son San Cristóbal, Santa Cruz, Santa María o Floreana e Isabela. Es importante señalar que el área habitada del archipiélago corresponde al 3\% del territorio insular. Sin embargo, el impacto que este genera afecta a todas las islas.

El aumento del turismo y de la población crea más presión sobre los recursos naturales de las islas, y trae consigo todos los problemas del crecimiento urbano que se dan en el Ecuador continental, como son acumulación y falta de respuesta frente a la disposición de desechos sólidos, baja calidad de los servicios básicos relacionados con el saneamiento ambiental y dotación de energía ${ }^{18}$.

Galápagos es una provincia absolutamente dependiente del continente. Esto se puede evidenciar a través de la forma en que se hace el

15 En 1979 aproximadamente 11000 turistas visitaron las islas. En 1982 alrededor de 17 000; en 1987, 32500 personas Ilegaron para conocer Galápagos. Alrededor de 40000 visitantes llegaron a Galápagos desde 1992 y las cifras de 1998 sobrepasan los 60000 visitantes.

16 La provincia de Galápagos entre 1982 y 1990 presentó la segunda tasa de crecimiento poblacional del Ecuador (5.9\%), que entre 1990 y 1998 aumentó a $6.4 \%$.

17 Varea Anamaría. 1997. "El Desencanto del Paraíso" en Ecologismo Ecuatorial. CEDEP-Abya-Yala. Quito-Ecuador.

18 Comisión de Comunidades Europeas. 1994. "Diagnóstico de la situación de las Islas Galápagos y recomendaciones para su Gestión Ambiental". BruselasBélgica.

- Fundación Charles Darwin para las Islas Galápagos, 1992, "Indicadores regionales de Galápagos". 1992.

- Varea Anamaría. 1997. "El Desencanto del Paraíso" en Ecologismo Ecuatorial. CEDEP-Abya-Yala. Quito-Ecuador. 
abastecimiento de productos, la manera en que está concebido el transporte terrestre, la planificación de las urbes y su dotación de servicios básicos ${ }^{19}$.

El derrame de combustible del buque Jessica, en marzo de 2001, puso en evidencia la vulnerabilidad de las islas por ser totalmente dependientes del continente para su abastecimiento. A fin dar respuestas alternativas para la dotación de energía a partir de 2002 el Programa de las Naciones Unidas para el Desarrollo, el Ministerio del Ambiente y los gobiernos locales desarrollan iniciativas para dotación de energías no contaminantes y renovables, como la energía eólica y la solar.

La biodiversidad de Galápagos está amenazada por el aumento de la población, por la presión del sector pesquero, por el incremento de la operación turística y la introducción de especies y deterioro del entorno natural. El aumento de la población multiplica la movilidad de personas y materiales entre las islas y el continente y entre las islas, lo que implica mayor circulación de gente y materiales incrementando los riesgos de introducción y dispersión de especies exóticas. Esta situación pone en peligro el aislamiento en el que estaba el archipiélago, condición que determinó el desarrollo de procesos evolutivos únicos en las islas.

A fin de mitigar estos impactos se han modificado las leyes y normas que rigen estas actividades en las islas, lo que ha conllevado a que se produzcan cambios institucionales para poder aplicarlas. La Ley de Régimen Especial para la provincia de Galápagos se presentó en octubre de 1997 y fue aprobada en febrero de 1998. Los temas más debatidos en la Ley han sido el control de inmigración, la actividad pesquera en la Reserva Marina de Galápagos, la distribución y utilización de los ingresos generados por los visitantes al Parque Nacional Galápagos y la

\footnotetext{
19 Paz y Miño. Guillermo. "Problemas ecológicos y perspectivas de manejo en la Amazonia ecuatoriana". En Amazonia nuestra-una visión alternativa. Quito. Abril de 1991. Ed. CEDIME. Abya-Yala. ILDIS. p.251.

- Ruiz Lucy (comp.). 1991. "Amazonia Nuestra: una visión alternativa". CEDIME. Abya-Yala. ILDIS. Quito-Ecuador.

- Ruiz Lucy (coord.). 1993. "Amazonia: escenarios y conflictos". CEDIME. Comisión V Centenario. ILDIS. FLACSO. Abya-Yala. Quito-Ecuador.

- Abya Yala. Tierra Viva. ILDIS. 1988. "Amazonia presente y...?”. Quito-Ecuador. Esta publicación recoge las ponencias del seminario con el mismo nombre y fue uno de los primeros eventos que a la época desató el debate sobre la problemática ambiental en la Amazonia.

Foro Amazónico.
} 
organización de las instancias de administración y control de las islas. La Nueva Ley de Turismo pone en riesgo la conservación de las islas.

\section{Amazonia ecuatoriana}

La Amazonia ecuatoriana, constituye el área geográfica más grande del Ecuador, ocupa aproximadamente el $50 \%$ de la superficie del país, con una superficie de $131137 \mathrm{~km}^{2}$. El país posee el 2\% de la Amazonia, sin embargo, no se puede subestimar la importancia de su conservación, para la región y para el país. Las tierras altas de esta región, en el Ecuador, han sido identificadas como un área de altísima biodiversidad, conocida como un "hot spot" (punto caliente, área de gran biodiversidad y endemismo). La preservación de la Amazonia es una necesidad nacional, regional y global y los argumentos que sustentan este punto, han sido debatidos y analizados en múltiples foros y publicaciones ${ }^{20}$.

En la Amazonia las poblaciones indígenas mantuvieron sus tradicionales procesos productivos sobre la base de la recolección de frutos silvestres, caza de animales y cultivos itinerantes de pequeñas parcelas, por medio de roza y quema, que permitía la posterior recuperación ecológica. En muchas comunidades, esta relación armónica con el entorno ha cambiado radicalmente por las presiones del mercado que están cambiando estas prácticas tradicionales, que determina una fuerte presión sobre su entorno natural.

La industria hidrocarburífera ha propiciado la tala del bosque tropical, a más de que ha favorecido un desordenado proceso de colonización de la región. De otro lado, esta actividad, al no usar tecnología adecuada, ha determinado un serio impacto al medio ambiente amazónico, contaminando suelo, agua y aire ${ }^{21}$. La contaminación generada por la industria, sin duda, amenaza la biodiversidad y ha traído serios problemas de salud a los moradores del sector, quienes han presentado sus

20 Amazonia sin mitos. BID. PNUD. TCA. Editorial Oveja Negra. 1994. p 253.

- Bravo. Elizabeth. La biodiversidad en la Amazonia: un recurso estratégico. En Amazonia por la vida: debate ecológico sobre el problema petrolero en el Ecuador. pp 70-72. Acción Ecológica. Quito. 1993.

21 Kimerling Judith. FECUNAE. 1993. "Crudo Amazónico". Abya-Yala. QuitoEcuador. 
denuncias a través de varios mecanismos, a nivel local, nacional e internacional $^{22}$.

La mala práctica petrolera en el Ecuador fue un tema que trascendió a nivel internacional, en donde se destacaron, sobre todo, la demanda legal presentada en las cortes norteamericanas por las poblaciones afectadas de la Amazonia ecuatoriana, a la compañía Texaco, para que se reparen los daños ocasionados y se indemnicen a las personas afectadas. La demanda legal frente al Tribunal de Aguas de la Haya también fue un aspecto debatido y difundido. En el 2004 la demanda a la Texaco se ventila en un juzgado en Lago Agrio.

En la Amazonia el cultivo de palma africana, ha implicado también una tala significativa de selva; alrededor de 20000 ha de floresta tropical han sido reemplazadas por este monocultivo.

En la región las áreas involucradas en el Sistema Nacional de Áreas Protegidas son los parques nacionales Yasuní y Sangay (1979), la reserva ecológica Cayambe-Coca (1979), así como la Reserva Faunística Cuyabeno (1979) y la Reserva Biológica Limoncocha (1985); áreas que, a pesar de contar con planes de manejo, en términos generales no han sido objeto de ningún tratamiento especializado que las preserve de formas de ocupación que, curiosamente, las mismas políticas estatales han generado, como es el caso de la colonización y la actividad hidrocarburífera ${ }^{23}$.

A pesar de que la Amazonia es una región con una riqueza ecológica sobresaliente, estos aspectos para el Ecuador no han sido relevantes, pues esta región ha sido valorada sobre todo desde una perspectiva

\footnotetext{
22 Varea, Anamaría, Ortiz, Pablo, 1997, "Marea Negra en la Amazonia: conflictos socioambientales vinculados a la actividad petrolera en el Ecuador". AbyaYala. ILDIS.

FTPP - FAO. UICN. Quito. 1995. Este libro presenta la sistematización de siete estudios de caso que ponen en evidencia los impactos socioambientales generados por la actividad petrolera.

- Kimerling Judith. 1996. "El Derecho del Tambor: derechos humanos y ambientales en los campos petroleros de la Amazonia Ecuatoriana". Abya-Yala. QuitoEcuador.

- Centro de Derechos Económicos y Sociales. 1994. "Violaciones de Derechos en la Amazonia Ecuatoriana - Las consecuencias humanas del desarrollo petrolero". Abya-Yala. Hombre y Ambiente No. 30. Quito-Ecuador.

23 Little Paul. 1992. "Ecología Política del Cuyabeno". ILDIS. Abya-Yala. QuitoEcuador.
} 
económica, porque es allí donde se desarrolla la actividad hidrocarburífera, que cubre alrededor del 50\% del presupuesto del Estado. En contraste con esta gran riqueza ecológica y económica, en la región oriental se presentan condiciones de extrema pobreza ${ }^{24}$.

\section{Andes del Ecuador}

Los Andes atraviesan el Ecuador por su parte media. La región interandina y las estribaciones orientales y occidentales de la cordillera de los Andes, sobre los 1330 msnm, tiene una extensión de 7’564 238 hectáreas. En esta región las transformaciones del entorno han sido muy marcadas y están dados por una alta densidad poblacional y una alta actividad agrícola y agropecuaria, condiciones que han determinado la desaparición casi total del bosque andino.

Los bosques nativos fueron explotados desde la época de la colonia, se supone que estos cubrían originalmente una superficie de $102000 \mathrm{~m}^{2}$ y ya en 1958 habían descendido a 50 000. Los valles interandinos son las áreas más deforestadas del país, se estima que existe menos del $3 \%$ de la vegetación natural en los valles interandinos y apenas el 7\% de la vegetación sobre los $2000 \mathrm{~m}$ de altura.

A diferencia de la Costa, los bosques de la Sierra de la vertiente oriental y los de la región suroriental conservan alrededor del $75 \%$ de su cobertura original. Según, los bosques de la sierra norte y centro, el matorral húmedo montano de Andes del Centro y Norte se encuentran en peligro crítico de extinción, ya que han perdido más del $75 \%$ de su área original $^{25}$.

\footnotetext{
24 Ruiz, Lucy, Varea, Anamaría, 1993, Amazonia: Tanta riqueza y tanta pobreza, artículo publicado en el diario El Comercio en 1993. Lucy Ruíz.

- UNICEF, 1992, "Situaciones específicas. Pueblos indígenas de la Amazonia ecuatoriana". UNICEF. Quito.

- Estrella. Eduardo; Vallejo. Francisco. "Situación de las madres y los niños en la Amazonia ecuatoriana" - Salud, nutrición y crecimiento físico en la Amazonia. UNICEF. 1992.

- Ruíz Lucy. "Situaciones específicas. Pueblos indigenas de la Amazonia ecuatoriana". Estudio de caso - El pueblo Cofán. UNICEF. Quito. 1992.

25 Josse, Carmen, 2001, "La biodiversidad en el Ecuador - El Informe 2000", MAE, Ecociencia, Quito.
} 
La mayor parte del callejón interandino ya no cuenta con su cobertura vegetal original y todos los valles están destinados a la agricultura intensiva. Adicionalmente, en el callejón interandino la reforma agraria favoreció a sectores económicos minoritarios. A los indígenas y los campesinos se les otorgó tierras en laderas de considerable pendiente, que sometidas a intensas prácticas de monocultivo, han sufrido un acelerado proceso de deforestación y erosión. En algunas zonas de la región interandina la escasez de agua constituye uno de los serios limitantes para mejorar y asegurar la producción agropecuaria.

La conservación y manejo de estos reductos de bosques, diseminados a lo largo del callejón interandino, es un imperativo ecológico y cultural puesto que son reservas genéticas, protegen las cuencas hidrográficas, resguardan los suelos agrícolas de las partes bajas, evitan la erosión, y son un ecosistema sustentador de vida, del cual dependen muchas comunidades andinas ${ }^{26}$.

Estos factores de deterioro ambiental determinaron un aumento de la migración y un crecimiento desordenado de las ciudades, aspectos que serán puntualizados en el capítulo referente a centros poblados y ambiente.

En esta zona también hay que destacar la existencia de los páramos, formación de pajonal que se encuentra entre los 3500 y 4400 msnm. Este ecosistema, aunque todavía cuenta con áreas extensas, también ha sufrido alteración. Desde fines de los 90 el tema de la conservación y el manejo del páramo adquieren relevancia y se trabaja en propuestas e iniciativas tendientes a rescatar este importante ecosistema. El

26 CESA. 1991. "Campesinado y Entorno Ecosocial”. CESA. Quito-Ecuador. - CESA. 1992. "El deterioro de los Bosques Naturales del Callejón Interandino del Ecuador". CESA. Quito-Ecuador.

- CESA. 1991. "Usos tradicionales de las especies forestales nativas en Ecuador". CESA. Quito-Ecuador.

- Moya Ruth y Moreno Fernando. 1991. "La Comunidad Indígena Serrana y el Desa-fío de la Conservación de los Recursos Naturales". COMUNIDEC. QuitoEcuador.

- Maldonado, Ana María. 1991. "Mujeres y Árboles en el Ecuador". FAO-Holanda - Forest Service - DFPA. Quito-Ecuador.

- UICN. Intercooperation. "Bosques Nativos Andinos y sus Comunidades: caracterización e identificación de la problemática en Ecuador". Tomo I. UICN-IC. QuitoEcuador.

- UICN. Intercooperation. "Bosques Nativos Andinos y sus Comunidades: estudios de caso en Ecuador". Tomo II. UICN-IC. Quito-Ecuador. 
grupo de trabajo sobre páramo destaca la importancia de estos ecosistemas, sobre todo por su función reguladora en el ciclo del agua, donde actúa como esponja y su conservación garantiza las reservas de agua dulce, tan necesaria para los cultivos y demás actividades que se llevan a cabo en los valles.

Como propuesta para el rescate de los páramos algunas comunidades trabajan en la reintroducción de camélidos como vicuñas y alpacas. La necesidad de tierra ha determinado el uso agrícola de este suelo que tiene muy bajos rendimientos. Este ecosistema de alta montaña se ha visto afectado por una sobreexplotación y quema de los páramos y sobrepastoreo con especies ajenas al ecosistema.

La conservación de bosques de la vertiente occidental de los Andes también es importante pues son ecosistemas representativos que están bajo creciente presión, lo que determina la pérdida de biodiversidad. El impacto sobre los bosques se deriva de una tradición extractiva (madera, carbón, plantas ornamentales) y expansión de la frontera agrícola (palmito, banano, café, ganado) por colonos y por empresas. De otra parte, hay debilidad de la protección estatal y la cultura organizativa en la zona, que requiere fortalecerse, a través de actividades de producción, capacitación y valoración de los servicios ambientales (agua, suelos, estabilidad climática). Bajo estas consideraciones, en junio de 1997 la Embajada Real de Los Países Bajos y el PPD firmaron el proyecto "Conservación de Bosques ubicados en la vertiente occidental de la cordillera de Los Andes", para la implementación de iniciativas comunitarias para la conservación de bosques, bajo los mecanismos, procedimientos y políticas del programa. Esta experiencia ha sido sistematizada, lo que ha permitido conocer que se han fortalecido las actorías locales, se ha incorporado en las agendas de las organizaciones locales el enfoque de manejo y conservación de la biodiversidad y se está trabajando en la viabilidad económica de las propuestas ${ }^{27}$.

Para salvaguardar los ecosistemas de la región interandina, el Estado ha declarado áreas protegidas: Parque Nacional Cotopaxi, Área de Reserva Cayambe-Coca y Parque Nacional Podocarpus, Parque

27 Carpio, P., Toledo, E., 2001, "Iniciativas Comunitarias para el Manejo y Conservación de la Biodiversidad: sistematización de los proyectos de la vertiente occidental de los Andes - Ecuador", PPD/UNDP, Embajada de los Países Bajo, OFIS, Quito. 
Nacional Cajas, Parque Nacional Sangay, Reserva Pasochoa, Reserva Geobotánica Pululahua.

\section{La Costa ecuatoriana}

La Costa es la región que se extiende desde el océano Pacífico hasta las tierras bajo los $1300 \mathrm{msnm}$, de las estribaciones occidentales de la cordillera de los Andes. El ambiente de la región costera del Ecuador, en las últimas tres décadas, ha variado significativamente. La costa ecuatoriana ha sido la más afectada por la deforestación. Estudios hechos por Dodson y Gentry (1991) determinaron que en esta región solo queda el 4,4\% de la cobertura original de bosques naturales y sin embargo, los reductos que se encuentran en el noroccidente de la Costa están bajo severa presión de las compañías madereras y a inicios del siglo XXI la tasa de deforestación en esta área se calcula en un 1,9\%.

La alta deforestación en la Costa responde al hecho de que en la región la agricultura a gran escala para exportación se inicio ya en los 60 y tuvo un acelerado crecimiento. En las partes bajas de las provincias costeras, casi todos estos bosques fueron reemplazados por monocultivos a gran escala de palma africana y banano. Como todo monocultivo, su rendimiento requiere de altas cantidades de insumos y productos químicos, lo que ha generado serios impactos socioambientales.

En lo que se refiere a la producción bananera cabe señalar el uso del DCBP (dibromocloropropano), nematicida utilizado en el país, hasta 1985, en las plantaciones bananeras, que causó esterilidad en los trabajadores. Desde principios de los 90 los hombres afectados por este producto demandan de las compañías responsables de la producción y comercialización del producto (Royal Dutch Shell, Dow Chemical, Standard Fruit, United Brands y Oxidental Petroleum) una indemnización y para ello han apelado a las cortes norteamericanas, a fin de que este consorcio multinacional reconozca el daño causado ${ }^{28}$.

A partir de los 80 la expansión de la actividad camaronera influyó también en la transformación del entorno natural. Hasta fines de los

\footnotetext{
28 Este conflicto socioambiental lo analiza Carmen Barrera en su trabajo "Juicio de trabajadores bananeros a consorcio multinacional" publicado en Desarrollo Eco-ilógico.
} 
70 a lo largo de los $850 \mathrm{~km}$ de costa ecuatoriana, existían 203695 ha de bosque de manglar, los que desaparecieron aceleradamente pues entre 1969 y 1991 se construyeron, en áreas de manglar, alrededor 120000 ha de camaroneras. La tala del manglar ha traído serios impactos ambientales que se reflejan en el aumento de la erosión de las costas, cambios en la salinidad y temperatura del agua e incremento de la contaminación. Esta transformación del entorno natural ha determinado cambios en los patrones productivos y culturales de la zona. Comunidades que vivían de un manejo sostenido de este ecosistema: concheras, cangrejeros, carboneros, pescadores artesanales han tenido que buscarse otro medio de subsistencia ${ }^{29}$.

A fin de precautelar la conservación de los remanentes de manglar que aún quedan en la costa ecuatoriana, desde fines de 1990-1999 varias comunidades usuarias del manglar han sido designadas por el Ministerio del Ambiente como custodios del manglar y tienen a su cargo la conservación y el manejo de estos remanentes.

El impacto de la actividad camaronera, a más de causar una tasa elevada de deforestación en el bosque de manglar, ha tenido impactos propios del origen de su actividad. La producción camaronera, como todo monocultivo requiere de ingentes cantidades de insumos y tóxicos para el control de plagas y enfermedades. Desde 1990 la actividad camaronera estuvo afectada por el síndrome de Taura y por la mancha blanca que impactaron severamente y determinaron una baja en los niveles de producción y de exportación ${ }^{30}$.

Otros impactos socioambientales que se han evidenciado en la Costa ecuatoriana tienen que ver con la sobrepesca de varias especies, que determinó una baja en las tasas de captura y, por lo tanto, en los

29 IDEA. 1989. "Situación Actual de la Maricultura del Camarón y Estrategias para su Desarrollo". Instituto de Estrategias Agropecuarias. Quito-Ecuador. - PMRC. 1994. "Una aproximación participativa y adaptativa al Manejo Costero Integrado: Ocho años de experiencia en el Ecuador". Documento presentado en el Simposio Internacional sobre - Manejo Integrado de Recursos Costeros en Ecuador. Guayaquil 15-17 de noviembre de 1994. PMRC. CRC. URI. CAAM. Mimeo sin publicar.

30 Desarrollo Eco-ilógico, Op. Cit. presenta cuatro casos, sistematizados por Ana María Maldonado, que dan cuenta de poblaciones que protestan por la destrucción del manglar. 
ingresos del sector pesquero. La contaminación por desechos provenientes de varias fuentes deterioró la calidad del agua y esto incide en las actividades productivas. La inadecuada ocupación de playas ahuyenta el turismo y disminuye la calidad de vida de las poblaciones costeras ${ }^{31}$.

En las provincias costeras no solamente había el manglar como recurso boscoso; tierra adentro existían también exuberantes bosques tropicales. Según los estudios hechos por Dodson y Gentry y publicados en 1993, la mayor parte de la conversión de bosque en el Ecuador occidental ocurrió entre 1960 y 1980 y para 1988 quedaban como remanentes alrededor de $4800 \mathrm{~km}^{2}$ que equivale al $6 \%$ de la superficie original. Algunas de estas áreas en las que se encuentran estos remanentes son protegidos con el establecimiento del Parque Nacional Machalilla, la Reserva Ecológica Cayapas-Mataje, Mache-Chindul y Manglares Churute.

Como una propuesta que apoye la conservación y manejo de la biodiversidad el PPD/PNUD y el Fondo de contravalor Ecuatoriano Suizo - FOES decidieron hacer una intervención conjunta y juntar esfuerzos, en la Costa ecuatoriana, para apoyar procesos de manejo sostenible de recursos naturales y mejoramiento de las condiciones de vida de diversos sectores de la población ecuatoriana, favoreciendo y fortaleciendo las capacidades locales en la Costa. En este marco se apoyaron siete proyectos en la región Costa del Ecuador.

Los proyectos se fueron agrupando en función de los siguientes ejes conductores: afinidades temáticas, ubicación de las comunidades, complementariedad de las acciones. Este esfuerzo de sistematizaciónorganización derivó en la formulación de un conjunto de proyectos que cubren áreas de atención prioritarias y que además se corresponden con los ámbitos de trabajo de las dos entidades de financiamiento. En la zona de Manglaralto se ejecutaron los siguientes proyectos: apicultura y reforestación; unidades productivas integrales agroecológicas (granjas integrales); manejo de los recursos de la faja costera; generación de energía no convencional a partir de desechos orgánicos (biogás). En la zona de Puerto López los proyectos fueron: manejo productivo agroecológico y del

31 - Arriaga Luis. s/f, "Manejo integral de recursos costeros: experiencia del Ecuador". Documento presentado en el taller -Hacia un Desarrollo Integrado de la Zona Costera de la IV Región". La Serena - Chile.

- PMRC. CRC - URI. CAAM. 1994. "Informe Resumido del Simposio Internacional sobre Manejo Integrado de Recursos Costeros del Ecuador". GuayaquilEcuador. 
bosque al interior del Parque Nacional Machalilla (PNM) y en su zona de amortiguamiento; manejo de los recursos de la faja costera y en El Oro se trabajó las organizaciones comunitarias trabajaron en la custodia del manglar y crianza de conchas. Estos siete proyectos fueron parte del "Programa de manejo sostenible de recursos naturales y gestión participativa de comunidades costeras de la Costa ecuatoriana -PROMAGES-" ${ }^{32}$.

\section{Centros poblados y deterioro ambiental}

Las ciudades y centros poblados son un aspecto relevante en el deterioro de la biodiversidad. La mayor parte de la población mundial habita en las urbes y Ecuador no escapa a esta situación ${ }^{33}$.

La calidad de vida de la población tiene una relación directa con la situación en la que se encuentra su entorno natural y depende de cómo están y se manejan los recursos naturales. En el país el proceso de migración hacia las ciudades, debido a diversos factores entre los que está el deterioro ambiental, ha sido marcado. La migración no se dio solamente hacia las grandes urbes (Quito, Guayaquil, Cuenca, Ambato), sino también hacia zonas en las que se desarrollan actividades económicas importantes, como la Amazonia (extracción petrolera) y Galápagos (turismo).

En estas ciudades que emergían en regiones de importancia ecológica, habría sido deseable que se consideraran aspectos ambientales en el ordenamiento territorial y planificación, sin embargo, los patrones de expansión de estos centros poblados han reproducido y exacerbado, en muchos casos, el esquema caótico de asentamientos humanos medianos y grandes.

Al igual que otros países del Tercer Mundo en el Ecuador los problemas ambientales que afectan a la biodiversidad se dan por una insuficiente planificación y ordenamiento territorial y deficientes servi-

\footnotetext{
32 PPD, 2002, Boletín No. 6, Quito.

33 65\% de la poblacional nacional vive en áreas urbanas.
} 
cios en el manejo del agua, saneamiento y disposición de desechos sólidos, manejo de los desechos urbanos e industriales ${ }^{34}$.

A mediados de los años 90, a través de la propuesta de descentralización, se inicia un proceso de planificación local que toma en consideración el punto de vista de los diversos actores locales y para el año 2003 los municipios cuentan con un plan de desarrollo local, muchos de ellos consideran como eje de desarrollo la conservación y manejo de la naturaleza y la preservación del ambiente. Si bien el abordar el tema no resulta fácil por la falta de personal capacitado y de recursos económicos, en muchas alcaldías se han dado los primeros pasos en la creación de una unidad ambiental y se está motivando a la población a incorporar prácticas y actitudes diferentes frente al entorno natural.

En este entorno natural se encuentran también áreas silvestres circundantes, como remanentes de bosques en los que se origina el agua para el consumo del centro poblado o el agua para riego. Estas áreas anteriormente, pasaban desapercibidas en la planificación y eran subestimadas. En relación a la gestión de municipios pequeños, cuya vinculación con el área rural es más directa, es importante anotar que la cooperación internacional ha apoyado varias iniciativas innovadoras en el manejo y conservación de la biodiversidad, experiencias que pueden ser consideradas como propuestas pioneras a ser incorporadas y replicadas en una propuesta de Planificación Territorial Sustentable ${ }^{35}$.

Los síntomas de la inadecuada planificación se ponen de manifiesto en las ciudades grandes y medianas donde la expansión territorial de las urbes evidenció la carencia de planes de ordenamiento urbano, se

\footnotetext{
34 Carrión Fernando. 1994. "La Gestión Urbana: estrategias. dilemas y retos". Ponencia presentada en el Seminario

- Augusto Samaniego (compilador). 1993. "La Gestión Ambiental en el DesarroIIo Urbano". ILDIS. CONUEP. Instituto de Investigaciones de Ciencias Técnicas. Cuenca-Ecuador

- Barreto Rodrigo (coordinador). 1996. "Ciudades y Pueblos Saludables: lineamientos para la promoción de la salud en ciudades y pueblos del Ecuador". Convenio OPS-CIUDAD. Quito-Ecuador.

- NNUU-PGU. sin fecha. "Estrategias Ambientales Urbanas". Serie Gestión Urbana Vol. 9. PGU-NNUU. UNCHS. PNUD. Banco Mundial. GTZ. Quito-Ecuador.

35 Carpio, Patricio, Toledo, Edgar, 2001, "Innovaciones comunitarias para el manejo y conservación de la biodiversidad", PPD/FMAMIUNDP, Embajada de los Países Bajos, OFIS.
} 
produjo un crecimiento desordenado que ha causado graves impactos ambientales como la contaminación de los cursos de agua, uso inadecuado de suelos fértiles, contaminación del aire y del suelo ${ }^{36}$.

En las urbes es muy común observar la presencia de industrias y fábricas ubicadas en el corazón de barrios residenciales. Las emanaciones, ruidos y actividades propias de la producción significan un deterioro de la calidad de vida de los moradores.

El crecimiento acelerado de las ciudades determinó la ocupación de áreas no aptas para la vivienda, zonas de marcada pendiente, o inundables o con inestabilidad del suelo propensos a catástrofes naturales. En la mayor parte de los casos, las poblaciones más vulnerables son las que ocupan estas áreas.

Como parte de una insuficiente planificación, ordenamiento del espacio y uso del suelo cabe resaltar que en todas las ciudades del país hay un déficit de parques y áreas verdes. Las pocas áreas verdes que existen no se mantienen adecuadamente. En Quito la relación es de 2.2 $\mathrm{m}$ por habitante, cuando el índice mínimo en las ciudades de América Latina es de $7 \mathrm{~m}$ por habitante.

La mayor parte de gobiernos locales no cuenta con una instancia específica para mantener los espacios verdes y rehabilitar los parques, este no es un tema prioritario frente a las demandas de servicios básicos que se presentan.

La generación de desechos sólidos tiene una relación directa con el consumo y el crecimiento urbano, la cantidad de basura que genera un centro poblado es proporcional al número de habitantes, a mayor población, mayor generación de basura.

El problema del manejo de desechos sólidos está directamente relacionado con el crecimiento urbano, la deficiencia en el servicio de recolección, la disposición final de los residuos y la poca creatividad de los gobiernos locales para plantear respuestas creativas y apropiadas.

Desafortunadamente, en la mayor parte de las ciudades del país la disposición de basura no se hace técnicamente. En la mayor parte de centros poblados los desechos se acumulan en un lugar descampado, lo que genera malos olores provenientes del botadero a cielo abierto, en varias ocasiones los residuos se queman, produciendo una espesa capa

36 Varea Anamaría. Barrera Carmen. Maldonado Anamaría. 1997. "Conflictos Sociambientales en las Ciudades". CEDEP-Abya-Yala. Quito-Ecuador 
de humo que contribuye a la contaminación del aire. Esto tiene un costo social pues representa un riesgo para la salud y ambiental pues contamina aire, agua y suelo.

Cuando la disposición final de basura se hace de manera antitécnica propicia las reacciones alérgicas, sensibiliza las membranas nasales y provoca gripes y catarros frecuentes; es un lugar idóneo para la reproducción de ratas y moscas, animales que determinan la diseminación de enfermedades infecto-contagiosas; desde aquí se propagan bacterias que pueden resultar peligrosas. Muchos de estos botaderos, debido al crecimiento acelerado de la ciudad, están ahora en áreas densamente pobladas; tal es el caso del botadero de Zámbiza en Quito, que desde 1998 debía cerrarse y en el 2002 casi colapsa ${ }^{37}$.

La contaminación del aire se da principalmente por dos razones: las emanaciones de la industria y el parque automotor. En las últimas dos décadas la producción industrial y el parque automotor han demandado un uso considerable de combustibles fósiles, lo que ha generado contaminación de aire sobre todo en ciudades como Quito, que al encontrarse a $2800 \mathrm{msnm}$, presentan problemas de combustión. La relación entre la contaminación del aire y la biodiversidad no se ha demostrado en el país, pero es conocido que esta produce lluvia ácida y afecta la vegetación ${ }^{38}$.

La contaminación del aire provocada por las industrias se da en la medida en que las industrias no cuentan con los equipos técnicos necesarios para reducir la emisión de gases tóxicos, esto trae consigo serios riesgos de contaminación y afecta a la salud de sus habitantes.

Debido a la actividad industrial toneladas de gases se arrojan directamente a la atmósfera y gran cantidad de fluidos tóxicos se vierten a los cursos de agua. En este punto es importante considerar a la agroindustria y todos los vertidos de agrotóxicos que implican. Las industrias

\footnotetext{
37 Ladin, Carlos., Rodríguez, Rosa., Marchán, Magali, 1994. "Manejo de Desechos Sólidos en el Ecuador". Fundación Natura. Nina Comunicaciones. QuitoEcuador.

38 Es muy conocido el caso de la Selva Negra en Alemania que estuvo seriamente amenazada por la lluvia ácida.
} 
no toman las medidas preventivas necesarias y las instancias gubernamentales responsables no logran controlar esta contaminación ${ }^{39}$.

El deterioro de la calidad del agua en el Ecuador es probablemente el problema ambiental más serio que afecta al país y el que afecta directamente a la biodiversidad acuática, deteriora la calidad del líquido vital para consumo humano y para riego.

La mayor parte de las ciudades hay sistemas sanitarios precarios cuyas descargas van a dar directamente a los cursos de agua ubicados más cerca de los centros poblados. Esto determina que muchos ríos, lagos y lagunas soporten un alto nivel de contaminación, pues las aguas servidas y las aguas negras, los desechos domésticos y de las industrias, descargan agua, sin previo tratamiento, en los cursos de agua. El deterioro de las fuentes de agua tiene un serio impacto en la salud de las poblaciones y en la economía ${ }^{40}$.

Respecto al tratamiento de aguas negras es importante anotar que los municipios de Cuenca y Loja han hecho marcados esfuerzos por descontaminar las aguas de los ríos que atraviesan por esas ciudades a través de un sistema de tratamiento de aguas y manejo de desechos.

\section{Propuestas participativas y diversas}

Este capítulo da cuenta de un proceso de 10 años (1994-2004) en el que se han ejecutado 100 iniciativas locales en el manejo y conservación de la biodiversidad en Ecuador. La razón por la que se ha seleccionado este Programa de Pequeñas Donaciones para ilustrar iniciativas locales vinculadas con la conservación de la biodiversidad es el hecho de que existen pocas propuestas que apoyan este enfoque específicamen-

39 Jurado Jorge. 1990. "Industria y Medio Ambiente". Serie Información para Lideres del Ecuador No. 4. Fundación Natura. Quito-Ecuador.

- Fundación Natura. 1991. "Potencial Impacto Ambiental de las Industrias en el Ecuador - exploración preliminar y soluciones". Fundación Natura-EDUNATIII. Quito-Ecuador.

- Fundación Natura. 1993. "Gestión Ambiental en la Industria en el Ecuador Informe de 8 Seminarios con Representantes Industriales para Analizar Alternativas para Mitigar los Impactos Ambientales". Fundación Natura - EDUNATIII. Quito-Ecuador.

40 Da Ros Guiseppina. 1995. "La contaminación de aguas en el Ecuador: una aproximación económica". PUCE. Abya-Yala. Quito-Ecuador. 
te. El PPD es un fondo semilla que apoya iniciativas comunitarias que buscan enfrentar los problemas medioambientales globales desde lo local.

El Programa de Pequeñas Donaciones forma parte del Fondo para el Medio Ambiente Mundial (PPD/FMAM), que es un mecanismo de apoyo financiero para proteger el medio ambiente mundial y está destinado a países en vías de desarrollo. Actualmente, tiene programas en 64 países del mundo. El PPD/FMAM en el país es administrado por el Programa de las Naciones Unidas para el Desarrollo.

Este programa está orientado a dar respuestas locales a los problemas ambientales mundiales como son: la conservación de la biodiversidad, iniciativas que busquen atenuar los efectos del cambio climático, la desertificación, que trabajen en ecosistemas acuáticos compartidos entre varios países (aguas internacionales) y la sensibilización ciudadana para lograr disminuir el uso de los Contaminantes Orgánicos Persistentes (COPs).

El PPD busca que en los proyectos se cuente con la participación de hombres y mujeres de comunidades rurales del Ecuador y con el apoyo técnico de organizaciones no gubernamentales (ONGs). A través de estas iniciativas las comunidades pueden mejorar su calidad de vida, mejorando sus ingresos mediante el apoyo a iniciativas sostenibles que, además, permitan el fortalecimiento de las actorías locales.

La intervención del PPD en los últimos años ha permitido el fortalecimiento de capacidades locales de ONGs y de Organizaciones Comunitarias de Base (OCB's) en todo el país.

Hasta el momento el PPD/FMAM/PNUD ha tenido una fase piloto y dos fases operativas. La fase piloto se ejecutó entre 1994 y 1996. La primera fase operativa se ejecutó entre 1996 - 1998 y la segunda fase operativa se inició en 1999 hasta la actualidad. Hasta el momento este programa ha apoyado la ejecución de 95 proyectos en diferentes regiones continentales del país. 


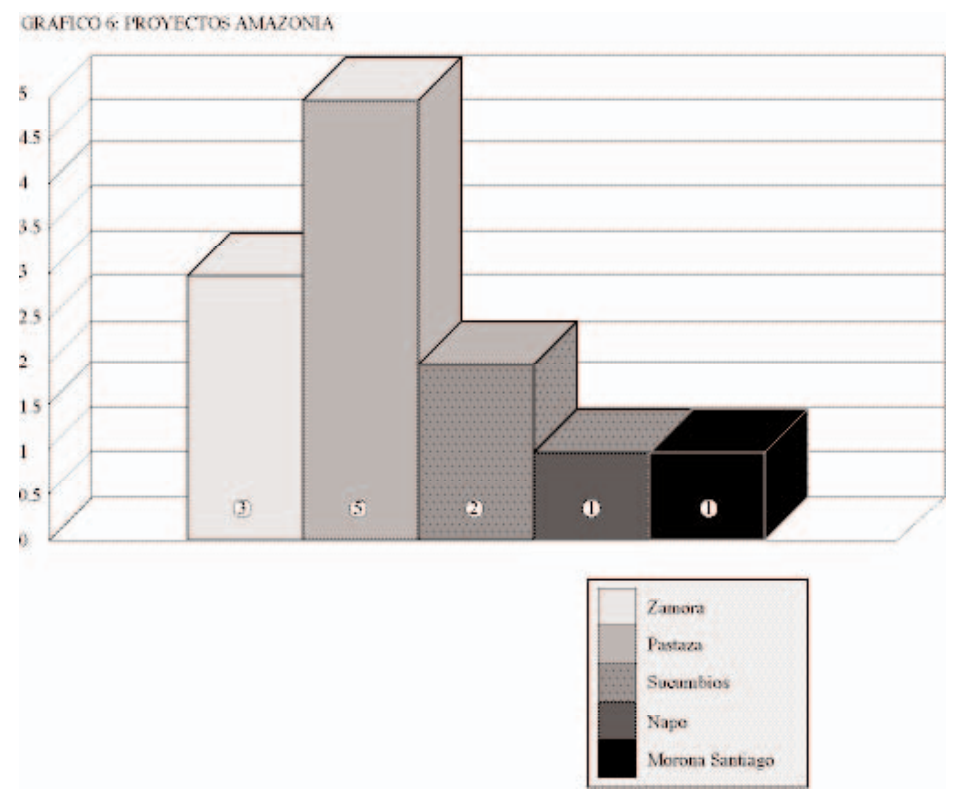

La gestión del PPD cuenta con el apoyo voluntario del Comité Directivo Nacional, que está cargo del seguimiento de la coordinación del programa, la selección de proyectos y la definición de los lineamientos y políticas que el programa debe seguir.

\section{GRÁFICO 7: TEMAS}

* Ecoturismo

* Plantas medicinales

* Recuperación de suelos

* Agroforestería

* Conservación de bosques

* Reforestación

* Producción orgánica
* Conservación humedales

* Granjas integrales

* Planes de desarrollo ambiental

* Producción en ciclo cerrado de animales y plantas nativas

* Zoocriadero

* Delimitación territorial

Para cada convocatoria el PPD solicita al CDN revisar la Estrategia Nacional del Programa que es la hoja de ruta del mismo en las que se especifican las áreas focales en las que trabaja el programa, los programas operativos y las actividades elegibles ${ }^{41}$.

41 Estrategia Nacional del Programa de Pequeñas Donaciones, 2003. www. undp/ppd.org.ec 
A fin de monitorear y dar seguimiento a las iniciativas locales se cuenta con la participación de ONGs, que son seleccionadas por el CDN. El sistema de seguimiento y monitoreo, a lo largo de estos años, ha ido afinándose y definiéndose mejor. Las organizaciones seleccionadas para esto durante este período han sido: CEPAES, OFIS, Ecociencia, Heifer, Ambiente y Sociedad, Oikos, Comunidec.

Las experiencias del PPD han sido difundidas a través de diferentes mecanismos: talleres, seminarios y publicaciones. En relación a estas últimas, en este boletín se reseñan dos documentos de sistematización: el primero vinculado con el bambú y el segundo con las experiencias de que se llevaron a cabo en la Vertiente Occidental de los Andes. Además el programa cuenta con una página Web en la que se presentan los lineamientos del mismo, así como una reseña de todos los proyectos ejecutados.

Este capítulo tiene la intención de analizar los enfoques orientadores y estrategias operativas del PPD, como un mecanismo para conocer los logros alcanzados y dificultades encontradas en este período a nivel comunitario y conocer de que manera este fondo semilla ha desencadenado proceso y ha permitido que germinen y florezcan nuevas propuestas en el país respecto en la conservación de la biodiversidad.

\section{Enfoques orientadores del PPD y estrategias operativas del PPD}

\section{Manejo y conservación de la biodiversidad}

La importancia de la biodiversidad en Ecuador, la ubicación de esta como un recurso estratégico y las estrategias para su manejo y conservación ha sido suficientemente explicada en la primera y segunda parte de este documento. En la segunda se analiza la situación de la biodiversidad en las diferentes regiones del país.

El PPD en estos 10 años cuenta con una cartera de proyectos amplia y diversa en la conservación de la biodiversidad. A través de estas iniciativas comunitarias se ha cubierto importantes áreas del país con iniciativas de conservación y manejo sustentable, en muchos casos estas están directa o indirectamente relacionadas con el sistema nacional de áreas protegidas. A partir de estos proyectos se puede identificar que 
existe un creciente interés en las comunidades por el tema de los recursos naturales. Los proyectos se han relacionado con la agrobiodivesidad y con la diversidad silvestre, cubriendo gran cantidad de especies y variedades en cada proyecto las mismas que cuentan con tecnología para su manejo. A partir de estas iniciativas se cuenta con un capital humano capacitado a nivel de comunidades en temas generales de manejo de recursos naturales.

Las tecnológicas innovadoras para la conservación de la biodiversidad se refieren a las innovaciones que las comunidades y ONGs implementan para el adecuado uso y manejo de biodiversidad. Las propuestas tecnológicas han permitido articular adecuadamente las necesidades de conservación de la biodiversidad con las necesidades de mejoramiento de las prácticas campesinas (agroforestería, forestería comunitaria, silvopasturas, forestería análoga, reproducción de plantas en viveros, rescate y recuperación de la agrobiodiversidad, manejo de plantas medicinales, manejo de recursos costeros).

A través de los proyectos se ha contribuido al manejo de la biodiversidad basándose en estudios de especies particulares e inventarios de flora y fauna que permitan conocer el estado del ecosistema en el que trabajó.

Las iniciativas comunitarias para el manejo de la biodiversidad han dado paso a que muchas familias campesinas se capaciten e incorporen prácticas sustentables y manejan su entorno natural con nuevos criterios tecnológicos.

El rescate de conocimientos tradicionales locales es un enfoque fundamental en el programa y algunos proyectos enriquecieron las propuestas tecnológicas a partir de estos.

\section{Fortalecimiento organizativo, participación y capacitación}

La propuesta PPD deben contar necesariamente con la participación comunitaria, en todo el ciclo del proyecto: diseño, ejecución, seguimiento y monitoreo y sistematización.

Fortalecer a las organizaciones que ejecutan proyectos PPD es un eje que atraviesa las propuestas y es fundamental para la adecuada ejecución del proyecto y para su sostenibilidad. A través de los proyec- 
tos PPD se ha identificado la conformación de organizaciones como comités, asociaciones, microempresas alrededor del manejo de la biodiversidad. De otra parte, varias de las agendas de organizaciones cuentan, ahora, con un enfoque ambiental y algunas específicamente el de biodiversidad.

A partir de este fondo semilla las organizaciones se han planteado mantenerse activas y desarrollar nuevas propuestas que permitan dar continuidad a la propuesta. Varias organizaciones han desarrollado capacidad de gestión tanto a nivel técnico como administrativo y de alianzas estratégicas con otros actores.

La capacitación es una actividad permanente en los proyectos PPD y va en diferentes vías: del programa a los ejecutores, de los ejecutores a los promotores y de los promotores a los miembros de la comunidad. Otra vía es del programa a las ONGs de Seguimiento y Monitoreo y de estas a los ejecutores, promotores y equipos técnicos. La capacitación tiene que ver con los enfoques orientadores del programa, las estrategias operativas y con aspectos administrativo - financieros y de gestión de proyectos.

A través de la capacitación se ha podido desarrollar capacidades técnicas a escala local en la búsqueda de sostenibilidad de los procesos. La capacitación y el diálogo de deberes han permitido ubicar el tema en el marco de preocupaciones de la comunidad y promover el inicio de acciones de gestión ambiental. Otros logros que se han destacado gracias a la capacitación son: involucrar a otros actores como municipios y centros educativos en el tema ambiental; generar múltiples alternativas para el uso sustentable de los recursos naturales y la biodiversidad y recuperar conocimientos locales sobre biodiversidad silvestre y agrobiodiversidad.

\section{Equidad y enfoque de género}

El enfoque se equidad y la incorporación del enfoque de género en los proyectos PPD es mandatorio. Este ha sido un gran desafío para el programa y para los ejecutores, sin embargo, ha valido la pena.

El objetivo de buscar equidad e incorporar el enfoque de género es lograr visualizar los roles, valorar el trabajo de las mujeres, la necesidad de procesos equitativos y la apertura de los mecanismos de toma 
de decisión comunitaria. La capacitación en género se la trabaja a lo largo del proyecto insistiendo y sugiriendo mecanismos para incluir a las mujeres como socias individuales y activas, tanto en la organización de base como en el proyecto y definiendo sus intereses y necesidades respecto al uso, acceso y control de los recursos naturales ${ }^{42}$.

La capacitación en género plantea incluir a la mujer en los proyectos en condiciones beneficiosas para ella y para la comunidad, protegiendo la armonía entre la participación de la mujer en los proyectos con las labores tradicionales que realiza. A lo largo del proceso se genera información más específica sobre lo que es género y la importancia que tiene su utilización en los proyectos de desarrollo y conservación y se afirma el proceso de valoración cultural con la recuperación de "identidad y pertenencia" individual y colectiva, en muchos casos en torno a propiciar su organización y control de actividades productivas ligadas uso, acceso y control de la biodiversidad, lo que potencia su posición para la plena participación de la mujer en la toma de decisiones.

42 EI PPD no cuenta con una metodología específica para la incorporación del enfoque de género en los proyectos para la conservación de la biodiversidad. Los aportes generados a mediados de los 90 han sido un apoyo para las ONGs de S\&M.

- Balarezo Susana. 1994. "Guía Metodológica para Incorporar la Dimensión de Género en el Ciclo de Proyectos Forestales Participativos". FAO: FTPP. DFPA. DFC; USAID. Quito-Ecuador.

- Rosero Rocío y Reyes Ariadna. 1995. "Género y Equidad: manual de metodología de trabajo con mujeres rurales". Comunidad Europea. MAG. Proyecto de Desarrollo de la Mujer Rural en la Provincia del Chimborazo. Quito-Ecuador.

- Cuvi María. 1995. "Integrando el Enfoque de Género en el Desarrollo Forestal Participativo" Memorias del Seminario Latinoamericano; FAO: FTPP. DFC; PAFT. Quito-Ecuador.

- Arguello Silvia. Jácome Rosario. Moncayo Ramiro. 1995. "Género en Proyectos de Desarrollo. Guía para extensionistas y promotores: de la teoría a la práctica". CESA. COTESU. IC. Quito-Ecuador.

- Wilde Vicki. Vainio-Manttila. 1995. "Gender Analysis and Forestry: training package". FTPP-FAO. Rome-ltaly.

- PAFE. 1997. "Las mujeres en la planificación forestal del Ecuador". Memorias del Taller - Integrando el enfoque de género en el Plan de Acción Forestal para el Ecuador - PAFE". Proyecto FAO-INEFAN-Holanda. Apoyo a la Implementación del PAFE. Quito-Ecuador.

- Poats. Susan.; "La dimensión de género en el manejo de conflictos socioambientales: una exploración preliminar". Ponencia preparada para el seminario internacional ILDIS. UICN. UPS. FTPP/FAO Manejo Alternativo de Conflictos Socioambientales. Mimeo sin publicar. Quito. 1995. 
A pesar de que el tema se inicia con el proyecto la interiorización del mismo requiere de un proceso más largo, empleando métodos integrales que consideren capacitación en el tema para los técnicos y promotores, así como la validación del proceso en el trabajo cotidiano con la comunidad, respetando sus condiciones culturales propias. Con ello se podrá lograr un impacto mayor y permanente en la conservación, desarrollo comunitario y en la equidad social.

$\mathrm{El}$ análisis de este enfoque permite identificar que aún se asigna a las mujeres actividades vinculadas a sus roles tradicionales, sin embargo, existe un reconocimiento de sus fortalezas sobre su saber acumulado en el manejo de la biodiversidad como son: plantas ornamentales, medicinales y alimentarias. A través de los proyectos se ha propiciado la constitución de organizaciones de mujeres, en esos espacios, las mujeres han encontrado los elementos de la identificación y solidaridad de género posibilitando visualizar las diferencias y plantearse nuevas relaciones con equidad. Se evidencian avances en la concienciación sobre la participación en pareja y por ende disminución de actitudes machistas.

\section{Acompañamiento y evaluación de procesos}

El proceso de seguimiento y acompañamiento técnico es una herramienta importante para monitorear los proyectos y establecer estrategias y lineamientos de intervención para el PPD. La comunicación dinámica entre los ejecutores del proyecto y una visión externa, ha posibilitado el enriquecimiento de la ejecución gracias a las visitas periódicas de los equipos técnicos, de la organización de talleres de capacitación y de encuentros para intercambio de experiencias. Este proceso es muy positivo por las características que tienen los proyectos: integrales, de corta duración y muy participativos.

El sistema de seguimiento y evaluación (SISE/PPD) cuenta con una serie de "principios" de funcionamiento, una metodología establecida y algunos instrumentos de sistematización y reporte ${ }^{43}$. Este sistema está enfocado al seguimiento y cumplimiento de las actividades previs-

\footnotetext{
43 PPD/ Comunidec, 2002, Sistema de Seguimiento y Evaluación para el Programa de Pequeñas Donaciones - SISE/PPD, documento de trabajo - sin publicar.
} 
tas por los proyectos y al acatamiento de las metas programadas. El grado de observancia de los objetivos de cada proyecto y el nivel de respeto de los objetivos del Programa están muy débilmente tratados, esto responde a que, el corto período de ejecución de los proyectos (uno o dos años) y las limitaciones económicas del apoyo financiero, hacen difícil evaluar objetivos muy generales o muy ambiciosos cuyos impactos solo pueden percibirse en el mediano y largo plazo.

En el proceso de seguimiento y acompañamiento se realizan visitas trimestrales, talleres con enfoque de género, y se mantiene una comunicación constante con los ejecutores (correo electrónico o telefónicamente) y se hace la entrega de informes periódicos a la comunidad sobre el seguimiento. Esto ha permitido detectar problemas y sugerir soluciones, antes de que estos se conviertan en obstáculos de mayor gravedad que pongan en peligro la ejecución de los proyectos.

El proceso de seguimiento y asistencia técnica concluye con una autoevaluación por parte de los ejecutores que ayuda a complementar la visión del proceso, para luego sistematizar las experiencias en un informe final.

La metodología manejada es participativa y plantea medir los logros en función de los objetivos de los proyectos y de las políticas de conservación comunitaria de recursos que promueve el PPD.

El mecanismo de seguimiento y asistencia técnica, implementado a través de las ONGs ha permitido mantener una relación permanente y periódica con los ejecutores de proyectos. El mayor esfuerzo de los equipos de seguimiento y asistencia técnica ha estado en enfatizar el objetivo de conservación de biodiversidad entre las acciones de los proyectos y evitar frecuentes tendencias a acciones tradicionales de desarrollo rural $^{44}$.

Los equipos de seguimiento han aportado, además, asesorando a la Coordinación Nacional del PPD y al Comité Nacional respecto a las medidas que se deben adoptar en la ejecución global del proyecto y en relación a apoyos directos de asesoría técnica, organizativa, de mantenimiento y apertura de relaciones entre proyectos y entre ONGs.

44 Candaele, Michael, 2003, "Evaluación de las ONGs de Seguimiento y Monitoreo", documento de trabajo PPD - sin publicar. 


\section{Sostenibilidad de las propuestas y alianzas estratégicas}

El PPD es un fondo semilla que ha apoyado casi 100 iniciativas para el manejo y conservación de la biodiversidad, en algunos casos financiando actividades específicas dentro de un proceso más amplio y en otros apoyando iniciativas de organizaciones, que por primera vez ejecutan un proyecto, directamente bajo su responsabilidad. En algunos casos estos proyectos han permitido desencadenar proceso en otros las experiencias, luego del financiamiento del PPD, no se han podido sostener. En el año 2002 OFIS realizó un estudio en el que determinó cuáles son los determinantes para la sostenibilidad de los proyectos ${ }^{45}$.

La mayor parte de los proyectos que lograron identificar y desarrollar alternativas económicas para mitigar el avance del deterioro sobre la biodiversidad se han mantenido activos. El nivel de generación de conocimientos sobre el potencial de muchos recursos, hasta ahora sin aprovechamiento comercial, también es un factor importante. A través de los proyectos PPD se ha podido constatar la conformación de organizaciones económicas campesinas, que poco a poco van fortaleciendo en sus conocimientos respecto a temas empresariales y en algunos casos se ha logrado inclusive la generación de algunos puestos de trabajo renumerado.

Las alianzas estratégicas se refieren a las modalidades que los actores vinculados con el proceso, a nivel nacional y local, concertan para generar impactos más sostenibles para la conservación de la biodiversidad.

A través de los acuerdos que los ejecutores han definido con actores locales (universidades, gobiernos locales, otras ONGs, instituciones gubernamentales, entre otras) se ha podido ubicar el tema ambiental como eje articulador de esfuerzos institucionales en comunidades, parroquias y cantones.

\footnotetext{
45 Carpio, P. Falconí, M., Toledo, E., 2003, "Innovaciones comunitarias para el manejo y conservación de los recursos naturales y el mejoramiento de la calidad de vida: cambios y sostenibilidad", propuesta que se ha publicado y difundido por Myka - Chorlaví, en la conferencia electrónica (2003) sobre "Acción Colectiva y mejoras en las condiciones de vida de las poblaciones rurales".
} 
Los proyectos PPD han abierto espacios de concertación sobre el tema ambiental con gobiernos locales ${ }^{46}$. A través de las alianzas estratégicas muchas iniciativas han logrado insertarse en propuestas más amplias de gestión ambiental con instituciones públicas y privadas para darle continuidad a las iniciativas PPD.

Las alianzas estratégicas permiten, en muchos casos, dar continuidad a los proyectos y garantizar su sostenibilidad. El programa desde la coordinación tiene un limitación y es el hecho de que da seguimiento a los proyectos mientras tiene compromiso con el aspecto financiero, pero luego de los dos años de ejecución, lamentablemente, no les sigue la pista y no tiene mecanismos para medir sus impactos. Bajo estas consideraciones se ha definido un plan de alianzas estratégicas que busca definir cómo los proyectos pueden ser apadrinados por redes, asociaciones o coordinaciones que tienen experiencia en el tema en el que los proyectos han trabajo. En el año 2003, con estos objetivos, se suscribieron proyectos con la Coordinadora Ecuatoriana de Agroecología (CEA), con la Asociación Ecuatoriana de Ecoturismo (ASEC) y con la Iniciativa de Biocomercio (IB/EcoCiencia - CORPEI). Se está formulando, actualmente una propuesta de trabajo conjunto con el Proyecto Páramo y el Grupo de Trabajo de Páramos (GTP).

46 Feliú, A., 2003, "Relación entre proyectos PPD y gobiernos locales", PPD, documento para la discusión interna. Los resultados de este documento determinaron que el Comité Directivo Nacional del PPD, en la convocatoria a presentación de proyectos lanzada en el 2003, se estableciera como criterio de elegibilidad el que las propuestas están enmarcadas en el Plan de Desarrollo Local. 
